\title{
Correlação de acamamento com rendimento de grãos e outros caracteres de interesse agronômico em plantas de trigo
}

\author{
Correlation of lodging with grain yield and other agronomically important traits in wheat plants
José Antonio Gonzalez da Silva ${ }^{1}$ Fernando Irajá Félix de Carvalho ${ }^{2}$ Antonio Costa de Oliveira ${ }^{1}$ Eduardo Alano Vieira ${ }^{3}$ Giovani Benin $^{1}$ Igor Pires Valério ${ }^{1}$ Marcos Fontoura Carvalho ${ }^{1}$ Taciane Finatto $^{1}$ Cyrano Cardoso Busato ${ }^{1}$ Guilherme Ribeiro ${ }^{1}$

\section{RESUMO}

A seleção indireta visando ao incremento no rendimento de grãos pelos seus componentes primários bem como a resistência ao acamamento podem representar estratégias eficientes a serem adotadas para otimização do ganho genético em trigo. Nesse sentido, o objetivo do trabalho foi evidenciar caracteres que possibilitem identificar genótipos de elevado rendimento de grãos e resistentes ao acamamento através de seleção indireta. O experimento foi conduzido no Centro Agropecuário da Palma, em Capão do Leão/RS utilizando dezenove genótipos de trigo em delineamento de blocos ao acaso, com três repetições. Nas condições deste estudo, o peso hectolítrico pode ser empregado de maneira eficiente na seleção indireta, visando ao incremento no rendimento de grãos, no peso médio de grãos, número de grãos por espiga e no peso de espiga. O caráter peso de espiga evidenciou elevado efeito indireto sobre o rendimento de grãos, podendo ser empregado na seleção indireta pela facilidade de mensuração. A linhagem TB 951 é indicada como excelente fonte de resistência ao acamamento em trigo, podendo contribuir para elevar o comprimento de espiga, o número de espigueta por espiga, o peso de espiga e o número de grãos por espiga.

Palavra-chave: seleção indireta, análise de trilha, Triticum aestivum L., melhoramento de plantas.

\section{ABSTRACT}

The selection in yield primary components and lodging resistance with goal of increasing grain yield can represent efficient strategies for optimizing genetic gain in wheat. In this sense, the objective of the present work was to detect characters that enable the identification of high grain yield

\begin{abstract}
potential and lodging resistant genotypes through the use of indirect selection. The experiment was conducted at the Centro Agropecuário da Palma, Capão do Leão/RS, consisting of nineteen wheat genotypes arranged in random block design with three replications. In this work conditions the hectoliter weight can be efficiently used through indirect selection aiming at increasing grain yield, average grain weight, number of grains per ear and ear weight. The character ear weight showed high indirect effect on grain yield and can be used for indirect selection due to its ease of measurement. The line TB 951 is indicated as an excellent source for lodging resistance in wheat, and can contribute to increase ear length, number of spikelets per ear, ear weigh and number of grain per ear.
\end{abstract}

Key words: indirect selection, path analysis, Triticum aestivum L., plant breeding.

\section{INTRODUÇÃO}

A resistência ao acamamento é um caráter de grande importância na lavoura de trigo e na de diversos outros cereais. No Brasil, genótipos de trigo resistentes ao acamamento passaram a ser extremamente desejáveis em função da aplicação de doses mais elevadas de nitrogênio nas lavouras e do emprego de novas tecnologias. Quando os colmos apenas inclinam e não se dobram, os grãos não sofrem prejuízos, possibilitando assim o processo regular de amadurecimento. Entretanto, se os colmos dobram e quebram, há evidentemente interrupção no movimento dos fotoassimilados, que não podem mais chegar à

\footnotetext{
${ }^{1}$ Departamento de Fitotecnia, Faculdade de Agronomia Eliseu Maciel (FAEM), Universidade Federal de Pelotas (UFPel), Pelotas, RS, Brasil.

${ }^{2}$ Departamento de Fitotecnia, FAEM/UFPel, Campus Universitário, Caixa Postal 354, 96010-900, Pelotas, RS, Brasil. Email:carvalho@ufpel.tche.br. Autor para correspondência.

${ }^{3}$ EMBRAPA-Centro de Pesquisa Agropecuária dos Cerrados, Planaltina, DF, Brasil.
} 
espiga, redundando em prejuízo não só na qualidade, mas, sobretudo, no peso médio do grão. Além de afetar a estrutura morfológica essencial para eficiente uso de carboidratos e sua translocação para os grãos, o acamamento tende a agravar os prejuízos de acordo com o estádio que ocorre, reduzindo o rendimento e a qualidade do produto final (ZANATTA \& OERLECKE, 1991). Em cereais, esses efeitos têm sido estudados em diversas regiões do mundo, com referências desde o início do século passado (BRADY, 1934), uma vez que o acamamento é considerado um fator determinante na redução do rendimento de grãos em até $60 \%$. Os efeitos do acamamento sobre o rendimento de grãos dependem do genótipo, da severidade e do tempo de ocorrência, sendo maiores as perdas em variedades de porte elevado e quando ocorre durante a fase reprodutiva (antese) (FEDERIZZI et al., 1994).

A introdução de genes de porte baixo permitiu grandes avanços no potencial de rendimento de grãos dos cereais, especialmente de trigo e arroz. A redução do porte possibilitou o cultivo desses cereais em locais altamente favoráveis ao seu desenvolvimento, como também a melhoria artificial do ambiente, particularmente através da irrigação e da aplicação de doses elevadas de adubos (STODDART \& LOYD, 1986). Contudo, os genótipos de porte alto podem expressar certo grau de resistência, evidenciando que o caráter também está associado a outros fatores como a quantidade de lignina produzida pelo tecido vegetal, ao diâmetro e a espessura do colmo (DOLINSKI, 1996). Desse modo, o grau de suscetibilidade de diferentes cultivares é variável, sendo encontrada resistência em genótipos extremamente distintos quanto aos demais caracteres de interesse dos melhoristas.

O rendimento de grãos em trigo é determinado por vários componentes: número de espigas por planta, número de espiguetas por espiga, número de grãos por espiga e por espigueta e peso médio do grão, dependendo diretamente dos fatores de origem genética e de ambiente (GRAFIUS, 1956; CRUZ, 2004). Portanto, não existem, provavelmente, genes específicos para rendimento de grãos, mas para os componentes, cuja interação determina a produtividade (GRAFIUS \& WIEBE, 1959). Caracteres de espiga correlacionados com rendimento de grãos representam um bom critério de seleção a ser adotado na busca de constituições genéticas de elevado potencial produtivo. Além disso, a proteção genética pelo uso de cultivares resistentes ao acamamento é a alternativa mais segura para incremento da produtividade e da qualidade do grão quando cultivadas em ambiente favorável a acamamento das plantas. Desse modo, o objetivo do trabalho foi avaliar o desempenho de dezenove genótipos de trigo hexaplóide no município de Capão do Leão/RS quanto à resistência e à suscetibilidade ao acamamento e seus efeitos sobre o rendimento de grãos e componentes primários, visando à seleção indireta, de modo a evidenciar caracteres que possibilitem identificar genótipos de elevado rendimento e resistentes ao acamamento.

\section{MATERIAL E MÉTODOS}

O experimento foi conduzido na safra agrícola de 2003, na área experimental do Setor de Fitomelhoramento, no Centro Agropecuário da Palma, em Capão do Leão - RS, com semeadura realizada em 30 de maio. Foram utilizados dezenove genótipos de trigo, empregando o delineamento de blocos ao acaso, com três repetições. A unidade experimental era composta de cinco fileiras de 3m de comprimento, utilizando uma densidade de semeadura corrigida para 160 sementes viáveis por $\mathrm{m}^{2}$, de modo que o número de plantas fosse o mesmo para todos os genótipos avaliados. As dimensões de cada parcela foram de 3,0 x 1m, com espaçamento de $0,2 \mathrm{~m}$ entre linhas. A semeadura foi efetuada manualmente e, logo após a emergência das plântulas, foi realizada adubação de base com 200 $\mathrm{Kg} \mathrm{ha}^{-1}$ da fórmula 5-20-20 (N-P $\left.\mathrm{O}_{5}-\mathrm{K}_{2} \mathrm{O}\right)$. No início do afilhamento do trigo, 30 a 45 dias após a emergência, foi realizada adubação nitrogenada em cobertura (RECOMENDAÇÃO DA COMISSÃO SULBRASILEIRA DE PESQUISA DE TRIGO, 2003). O controle de invasoras foi efetuado através de capinas manuais e da aplicação dos herbicidas de pósemergência: Basagran (Bentazon) e Ally (Metsulfuronmetil). Para controle de moléstias da parte aérea foi aplicado o fungicida Folicur 200 CE (Tebuconazole). Para controle de insetos durante a fase de alongamento do colmo e no início e fim da floração das plantas de trigo, foi utilizado o inseticida Symition (Fenitrothion).

Foram utilizados dezenove genótipos de trigo (BH 1146, BR 18, BR 23, BR 35, BRS 49, BRS 119, BRS 120, BRS 177, BRS 192, BRS 194, BRS 208, PF 950354, TB 951, CEP 24, CEP 29, RUBI, SONORA 64, ICA 1 e ICA 2). Os dez caracteres avaliados foram: comprimento da espiga (Ce), número de espiguetas por espiga ( $\left.\mathrm{Ne}^{-1}\right)$, peso da espiga (Pe), número de grãos por espiga $\left(\mathrm{Ng} \mathrm{e}^{-1}\right)$, peso de mil grãos (Pmg), peso do hectolitro $(\mathrm{PH})$, número de afilhos férteis por metro linear (AFML), rendimento de grãos (Rg), acamamento (ACAM) e estatura de planta (EST) por meio da análise de variância, comparação de médias pelo teste de Tukey e correlações fenotípicas. Para posterior análise dos coeficientes de trilha, foi utilizado o caráter rendimento 
de grãos (Rg) como variável dependente principal e os caracteres aferidos na espiga e o acamamento como variáveis independentes explicativas. Primeiramente, foi estimada a correlação genética (dados não apresentados) através do método proposto por STEEL \& TORRIE (1980) e, posteriormente, foram determinados os efeitos diretos e indiretos através da análise de trilha, método desenvolvido por WRIGTH (1923) e aperfeiçoado por LI (1975), que tem por objetivo o estudo da decomposição do coeficiente de correlação, de modo a avaliar se a relação entre duas variáveis é de causa ou efeito ou determinada pela influência de outra ou outras variáveis.

O rendimento de grãos foi determinado por meio da colheita e pesagem dos grãos das três linhas centrais de cada parcela, considerando como bordadura a primeira e a quinta linha. Para os componentes do rendimento, os caracteres número de grãos por espiga, número de espiguetas por espiga e comprimento da espiga foram obtidos através da média das determinações realizadas em dez espigas coletadas ao acaso nas três linhas centrais da parcela. O peso de mil grãos foi estabelecido por meio do valor da pesagem de 250 grãos multiplicado por quatro e, para estimar o peso do hectolitro, foram retiradas quatro repetições de 250ml de cada genótipo e pesadas. O caráter afilhos férteis por metro linear foi estimado pelo número de espigas, numa área de um metro linear no período de florescimento; o acamamento, pela percentagem de plantas acamadas, segundo o procedimento apresentado por SCHEEREN (1984), e a estatura de planta, medida do solo até a extremidade da espiga, excluindo as aristas.

As correlações genéticas foram estimadas a partir do quadrado médio esperado $\left(\mathrm{QM}_{\mathrm{E}}\right)$, através da análise de variância, conforme descrito por FALCONER \& MACKAY (1996). O grau de multicolinearidade da matriz de correlações entre as variáveis independentes do modelo de regressão $\left(\mathrm{X}^{`} \mathrm{X}\right)$ foi estabelecido com base no seu número de condições (NC), que é a razão entre o maior e o menor autovalor da matriz de correlação genética. Com $\mathrm{NC}<100$, a multicolinearidade foi denominada fraca e não constitui dificuldade para análise. Todas as análises estatísticas foram efetuadas com auxílio do programa computacional GENES(CRUZ, 2001).

\section{RESULTADOS E DISCUSSÃO}

Os caracteres avaliados em laboratório e a campo apresentaram diferenças significativas, em nível de $5 \%$ de probabilidade (Tabela 1). As amplitudes verificadas entre os valores mínimos e máximos revelam diferenças bastante acentuadas, permitindo prever a variabilidade existente para os diferentes caracteres analisados. Em relação ao coeficiente de variação, somente o caráter acamamento demonstrou valor elevado, caracterizando uma provável indução ao erro pelo pequeno número de repetições e tamanho da parcela, visto que os outros valores detectados podem ser considerados adequados para a estimativa dos demais caracteres. Também existe forte participação do ambiente na expressão do caráter que poderia ser reduzido pelo aumento no número de repetições, tamanho de parcelas e método mais eficiente de avaliação do acamamento. O método de avaliação do acamamento, mensurado apenas de forma visual, implica subjetividade na observação, indicando provavelmente não ser o mais adequado para avaliação do caráter. CRUZ (2002), estudando a genética do acamamento em trigo e a identificação do caráter para seleção, verificou que o método denominado de coeficiente de resistência do colmo (cLr) parece ser uma boa técnica para seleção indireta de planta de trigo resistente ao acamamento, sendo que os caracteres comprimento do pedúnculo, estatura de planta e índice do colmo têm sido indicados para seleção indireta visando à resistência em trigo.

Os valores médios da tabela 2 permitem discriminar fenotipicamente os dezenove genótipos de trigo, considerando os dez caracteres avaliados. Desse modo, é possível perceber que o genótipo TB 951 apresentou o maior Ce estando na classe "a”, seguido do genótipo PF 950354 e BR 23 formando a classe “b”, e as demais constituições genéticas formaram um grande grupo, originando a classe “c”. Para o $\mathrm{Ne} \mathrm{e}^{-1}$, a linhagem TB 951 também evidenciou o melhor desempenho junto com a cultivar BRS 49, indicando que mesmo dois genótipos que apresentam diferenças no Ce podem evidenciar valores similares de $\mathrm{Ne} \mathrm{e}^{-1}$. As cultivares CEP 29, BR 18, CEP 24, BRS 192, BH 1146, ICA 2, SONORA 64, ICA 1, RUBI, BRS 208 e BRS 194 apresentaram os menores valores, formando a classe “c”. Já os caracteres Pe e AFML evidenciaram apenas duas classes distintas, caracterizando várias constituições genéticas de elevados valores. Para o $\mathrm{Ng} \mathrm{e}^{-1}$, a linhagem TB 951 apresentou o melhor desempenho, com média de 55 grãos “a”, seguida dos genótipos BRS 119 e ICA 2, representando a classe “b”, com médias de 47 e 49 grãos por espiga, respectivamente, e BR 18, BH 1146 e SONORA 64 evidenciaram reduzido desempenho, estando na classe “e”. Para o caráter Pmg, os genótipos apresentaram três classes distintas, tendo como destaque a cultivar CEP 24 “a”, seguida da BRS 120, BR 18, BH 1146, BRS 208, e BRS 194 “b” e os demais genótipos situados na 
Tabela 1 - Resumo da análise de variância em dezenove genótipos de trigo para os caracteres medidos em laboratório: (Ce)= comprimento de espiga; $\left(\mathrm{Ne} \mathrm{e}^{-1}\right)=$ número de espiguetas por espiga; $(\mathrm{Pe})=$ peso de espiga; $\left(\mathrm{Ng} \mathrm{e}^{-1}\right)=$ número de grãos por espiga; $(\mathrm{Pmg})=$ peso de mil grãos; $(\mathrm{PH})=$ peso de hectolitro; $(\mathrm{Rg})=$ rendimento de grãos; e a campo: $(\mathrm{AFML})=$ afilhos férteis por metro linear; $(\mathrm{ACAM})=$ $\%$ de acamamento e $($ EST) $=$ estatura de planta. FAEM/UFPel, 2004.

\begin{tabular}{|c|c|c|c|c|c|c|c|c|c|c|c|}
\hline & & \multicolumn{10}{|c|}{$\mathrm{QM}$} \\
\hline & & $\mathrm{Ce}$ & $\mathrm{Ne} \mathrm{e}^{-1}$ & $\mathrm{Pe}$ & $\mathrm{Ng} \mathrm{e}^{-1}$ & Pmg & $\mathrm{PH}$ & AFML & $\mathrm{Rg}$ & ACAM & EST \\
\hline FV & GL & $(\mathrm{cm})$ & $(\mathrm{cm})$ & (g) & (n) & (g) & $\left(\right.$ g.cm $\left.{ }^{3}\right)$ & (n) & $\left(\mathrm{kg} \mathrm{ha}^{-1}\right)$ & (\%) & $(\mathrm{cm})$ \\
\hline Bloco & 2 & 0,8 & 2,4 & 0,2 & 6,7 & 5,6 & 1,28 & 76,8 & 71927 & 28,7 & 75 \\
\hline Gen & 18 & $3,1^{*}$ & $4,1^{*}$ & $0,3^{*}$ & $137,5^{*}$ & $61,7^{*}$ & $39,8^{*}$ & $785,2 *$ & $2026364 *$ & $3184,2 *$ & $489,0 *$ \\
\hline Res & 36 & 0,4 & 0,7 & 0,9 & 16,7 & 8,1 & 1,8 & 109,3 & 95333 & 54,3 & 21,7 \\
\hline Total & 56 & - & - & - & - & - & - & - & - & - & - \\
\hline Média & - & 9,2 & 16,5 & 2,1 & 41,1 & 38,9 & 75,6 & 98,3 & 3467 & 27,3 & 98,9 \\
\hline $\mathrm{CV} \%$ & - & 6,5 & 5,0 & 14,2 & 9,9 & 7,3 & 1,8 & 10,6 & 8,90 & 27,1 & 4,7 \\
\hline Min & - & 7,4 & 13,0 & 1,0 & 22,8 & 32,0 & 66 & 50 & 1550 & 0 & 65 \\
\hline Máx & - & 12,8 & 20,0 & 3,1 & 56,6 & 51,2 & 82 & 147 & 5316 & 95 & 120 \\
\hline
\end{tabular}

$(F V)=$ Fonte de variação; $(\mathrm{Gen})=$ Genótipo; $($ Res)= Resíduo; $(\mathrm{CV} \%)=$ Coeficiente de variação em percentual; $($ Min)= Valor mínimo encontrado; $($ Máx $)=$ Valor máximo encontrado; $\left({ }^{*}\right)=$ Significativo a $5 \%$ de probabilidade de erro.

Tabela 2 - Análise de médias para os caracteres medidos em dezenove genótipos de trigo no laboratório: (Ce)= comprimento de espiga; (Ne $\left.\mathrm{e}^{-1}\right)=$ número de espiguetas por espiga; $\left((\mathrm{Pe})=\right.$ peso de espiga; $\left(\mathrm{Ng} / \mathrm{e}^{-1}\right)=$ número de grãos por espiga; $($ Pmg $)=$ peso de mil grãos; $(\mathrm{PH})=$ peso de hectolitro; $(\mathrm{Rg})=$ rendimento de grãos, e a campo: $(\mathrm{AFML})=$ afilhos férteis por metro linear; $(\mathrm{ACAM})=\%$ de acamamento e $(E S T)=$ estatura de planta. FAEM/UFPel, 2004.

\begin{tabular}{|c|c|c|c|c|c|c|c|c|c|c|}
\hline \multirow[b]{2}{*}{ GEN } & \multicolumn{9}{|c|}{ Médias } & \multirow[b]{2}{*}{$\mathrm{EST}(\mathrm{cm})$} \\
\hline & $\mathrm{Ce}(\mathrm{cm})$ & $\mathrm{Ne} / \mathrm{e}^{-1}(\mathrm{n})$ & $\mathrm{Pe}(\mathrm{g})$ & $\operatorname{Ng~e}^{-1}(n)$ & Pmg(g) & $\begin{array}{c}\mathrm{PH} . \\
\left(\mathrm{kg}_{100 l^{-1}}\right)\end{array}$ & AFML(n) & $\begin{array}{c}\mathrm{RG} \\
\left(\mathrm{Kg} \mathrm{ha}^{-1}\right)\end{array}$ & $\begin{array}{c}\text { ACAM } \\
(\%)\end{array}$ & \\
\hline ТВ 951 & $11,8 \mathrm{a}$ & $19,4 \mathrm{a}$ & $2,6 \mathrm{a}$ & 55,0 a & 35,0 c & $75 \mathrm{c}$ & $87 \mathrm{~b}$ & $2457 \mathrm{e}$ & $0,6 \mathrm{~d}$ & $71 \mathrm{e}$ \\
\hline PF 950354 & $10,8 \mathrm{~b}$ & $17,2 \mathrm{~b}$ & 2,1 a & $43,0 \mathrm{c}$ & 38,9 c & $77 \mathrm{c}$ & $98 \mathrm{~b}$ & $2783 \mathrm{e}$ & 53,3 c & $116 \mathrm{a}$ \\
\hline BR 23 & $10,6 \mathrm{~b}$ & $17,4 \mathrm{~b}$ & $2,2 \mathrm{a}$ & 44,2 c & 38,2 c & $76 \mathrm{c}$ & $83 \mathrm{~b}$ & $4122 \mathrm{~b}$ & $2,3 \mathrm{~d}$ & $100 \mathrm{~b}$ \\
\hline BRS 177 & $9,7 \mathrm{c}$ & $16,9 \mathrm{~b}$ & 2,1 a & $45,1 \mathrm{c}$ & 36,3 с & $79 \mathrm{~b}$ & 117 a & 4809 a & $6,6 \mathrm{~d}$ & $100 \mathrm{~b}$ \\
\hline CEP 29 & $9,3 \mathrm{c}$ & $15,9 \mathrm{c}$ & $2,2 \mathrm{a}$ & $43,4 \mathrm{c}$ & 39,3 с & $76 \mathrm{c}$ & $93 \mathrm{~b}$ & 3933 c & $5,3 \mathrm{~d}$ & $91 \mathrm{c}$ \\
\hline BRS 120 & $9,2 \mathrm{c}$ & $17,0 \mathrm{~b}$ & 2,1 a & $38,5 \mathrm{~d}$ & $41,1 \mathrm{~b}$ & $78 \mathrm{~b}$ & $131 \mathrm{a}$ & 3611 c & $11,0 \mathrm{~d}$ & $103 \mathrm{~b}$ \\
\hline BR 18 & 9,2 c & $15,3 \mathrm{c}$ & $1,8 \mathrm{~b}$ & 30,7 e & $41,9 \mathrm{~b}$ & $69 \mathrm{c}$ & $81 \mathrm{~b}$ & 2438 e & $68,3 \mathrm{~b}$ & $80 \mathrm{~d}$ \\
\hline BRS 119 & $9,2 \mathrm{c}$ & $17,5 \mathrm{~b}$ & 2,3 a & $47,2 \mathrm{~b}$ & 37,7 с & $76 \mathrm{c}$ & $94 \mathrm{~b}$ & 3927 c & $18,3 \mathrm{~d}$ & $96 \mathrm{~b}$ \\
\hline BR 35 & $9,0 \mathrm{c}$ & $17,0 \mathrm{~b}$ & 2,2 a & $43,1 \mathrm{c}$ & 39,7 с & $74 \mathrm{c}$ & $88 \mathrm{~b}$ & $4111 b$ & $2,6 \mathrm{~d}$ & $103 \mathrm{~b}$ \\
\hline CEP 24 & $8,8 \mathrm{c}$ & $15,4 \mathrm{c}$ & 2,1 a & $35,2 \mathrm{~d}$ & 51,9 a & $78 \mathrm{~b}$ & 110 a & 3661 c & $70,0 \mathrm{~b}$ & 118 a \\
\hline BRS 192 & $8,7 \mathrm{c}$ & $16,2 \mathrm{c}$ & 2,6 a & $46,3 \mathrm{c}$ & 36,1 c & $79 \mathrm{~b}$ & $68 \mathrm{~b}$ & 3388 c & $3,3 \mathrm{~d}$ & $90 \mathrm{c}$ \\
\hline ВН 1146 & $8,7 \mathrm{c}$ & $14,6 \mathrm{c}$ & $1,6 \mathrm{~b}$ & 31,0 e & 45,3 b & $71 \mathrm{~d}$ & $95 \mathrm{~b}$ & $3105, \mathrm{~d}$ & 93,3 a & $106 \mathrm{~b}$ \\
\hline ICA 2 & $8,7 \mathrm{c}$ & $16,3 \mathrm{c}$ & 2,1 a & $48,6 \mathrm{~b}$ & $32,1 \mathrm{c}$ & $75 \mathrm{c}$ & $80 \mathrm{~b}$ & $2561 \mathrm{e}$ & $90,0 \mathrm{a}$ & $83 c$ \\
\hline BRS 49 & $8,7 \mathrm{c}$ & 18,3 a & $1,8 \mathrm{~b}$ & $32,0 \mathrm{~d}$ & 35,6 c & $71 \mathrm{~d}$ & $104 \mathrm{a}$ & $3166 \mathrm{~d}$ & $9,3 \mathrm{~d}$ & $110 \mathrm{a}$ \\
\hline SONORA 64 & $8,5 \mathrm{c}$ & $15,0 \mathrm{c}$ & $1,3 \mathrm{~b}$ & 27,0 e & 36,7 c & $67 \mathrm{e}$ & $99 \mathrm{~b}$ & $1577 \mathrm{f}$ & $16,6 \mathrm{~d}$ & $86 c$ \\
\hline ICA 1 & $8,4 \mathrm{c}$ & $16,5 \mathrm{c}$ & 2,0 a & $41,2 \mathrm{c}$ & $34,0 \mathrm{c}$ & $77 \mathrm{c}$ & $108 \mathrm{a}$ & 3638 c & $1,6 \mathrm{~d}$ & 115 a \\
\hline RUBI & $8,4 \mathrm{c}$ & $15,5 \mathrm{c}$ & 2,1 a & $38,0 \mathrm{~d}$ & $40,1 \mathrm{c}$ & $81 \mathrm{a}$ & $120 \mathrm{a}$ & 4550 a & $2,0 \mathrm{~d}$ & $96 \mathrm{~b}$ \\
\hline BRS 208 & $8,1 \mathrm{c}$ & $16,2 \mathrm{c}$ & 2,3 a & $42,6 \mathrm{c}$ & 44,4 b & $77 \mathrm{c}$ & $88 \mathrm{~b}$ & 3855 c & 55,0 c & $100 \mathrm{~b}$ \\
\hline BRS 194 & $7,5 \mathrm{c}$ & $16,7 \mathrm{c}$ & 2,1 a & $40,3 \mathrm{c}$ & $42,2 \mathrm{~b}$ & $75 \mathrm{c}$ & $118 \mathrm{a}$ & $4181 \mathrm{~b}$ & $8,3 \mathrm{~d}$ & $110 \mathrm{a}$ \\
\hline
\end{tabular}

Médias seguidas da mesma letra na vertical não diferem entre si pelo teste de Scott e Knott a 5\% de probabilidade.

Ciência Rural, v.36, n.3, mai-jun, 2006. 
classe “c”, conforme tabela 2. Para o PH, grande destaque ficou evidenciado para a cultivar Rubi, com

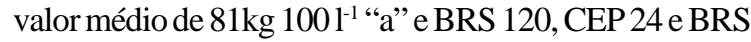
192 na classe "b” e os demais genótipos na classe "c". Pode ser observado que o genótipo TB 951, que apresentou os melhores desempenhos quanto ao caráter $\mathrm{Ce}, \mathrm{Ne} \mathrm{e}^{-1}$, Pe e $\mathrm{Ng} \mathrm{e}^{-1}$, evidenciou baixo desempenho para o Pmg e $\mathrm{PH}$.

Cruzamentos envolvendo a linhagem TB 951 com as cultivares Rubi, CEP 24 e BRS 177, podem representar boa alternativa na obtenção de constituições genéticas com elevado desempenho para as variáveis em estudo, levando em consideração a complementaridade dos caracteres de interesse pela formação de recombinantes desejáveis e pela possível seleção em populações segregantes. Além disso, a linhagem TB 951 evidenciou reduzida estatura e elevada resistência ao acamamento (Tabela 2), evidenciando os melhores desempenhos. Considerando o caráter rendimento de grãos, as cultivares Rubi e BRS 177 evidenciaram elevados valores médios, estando na classe “a”, seguidas da cultivar BR 23, BR 35 e BRS 194 "b”; ao contrário da SONORA 64 "f”, da TB 951, da PF 950354, da BR 18 e da ICA 2 “e”, que apresentaram os menores desempenhos.

Para o caráter ACAM, foi possível detectar grandes diferenças, discriminando genótipos que apresentam elevados valores de acamamento como BH 1146, ICA 2, BR 18, CEP 24, PF 950354 e BRS 208, que apresentaram valores de acamamento em percentagem de 93 “a”, 90 “a”, 68 “b”, 70 “b”, 53 “c” е 55 “c” respectivamente, ao contrário do genótipo TB 951 (0,6\%), BR 23 (2\%), BRS177 (6\%), CEP 29 (5\%), BRS 120 (11\%), BRS 119(18\%), BR 35(2\%), BRS 192 (3\%), BRS 49 (9\%), Sonora 64 (16\%), ICA 1(1\%), Rubi (2\%) e BRS 194 (8\%). No caráter EST, a linhagem TB 951 apresentou menor valor $(71 \mathrm{~cm})$, seguida do genótipo BR 18, com $80 \mathrm{~cm}$; entretanto, valores elevados de estatura foram encontrados nos genótipos PF 950354 (116cm), CEP 24(118cm), BRS 49 (110cm), ICA 1(115cm) e BRS $194(110 \mathrm{~cm})$. Além disso, valores intermediários foram evidenciados nos genótipos CEP 29, BRS 192, ICA 2, e Sonora 64, com médias de 91, 90, 83 e 86cm, respectivamente.

O exame dos coeficientes de correlação simples de suscetibilidade ao acamamento com rendimento de grãos e componentes primários em trigo (Tabela 3) apontou não haver significância na maioria das comparações analisadas, exceto para o caráter Ne $\mathrm{e}^{-1}$, indicando uma associação negativa, de modo que, com o aumento do percentual de plantas acamadas, ocorre a diminuição do $\mathrm{Ne} \mathrm{e}^{-1}$. Além disso, o caráter $\mathrm{Ne}$ $\mathrm{e}^{-1}$ apresenta associação positiva com $\mathrm{Pe}, \mathrm{Ng} \mathrm{e}^{-1} \mathrm{e}$ negativa com Pmg, possivelmente interferindo indiretamente nesses caracteres quando o ACAM influenciar o $\mathrm{Ne} \mathrm{e}^{-1}$.

A falta de associação existente entre a maioria dos caracteres estudados com o acamamento foi previsível, como verificado na tabela 3 , visto que muitas constituições genéticas resistentes ao acamamento foram menos produtivas do que outras que apresentaram elevado percentual de ACAM, o que é facilmente explicado pelo potencial genético produtivo da cultivar, favorecido pelas condições de ambiente. Além disso, a pouca interferência do acamamento no rendimento de grãos e de seus componentes provavelmente esteja relacionada ao estádio de desenvolvimento da cultura em que o evento tenha ocorrido, a pouca interferência, no ano de cultivo, de fatores como ventos fortes, chuvas excessivas e à própria característica intrínseca da cultivar. Para BRADY (1934) e ROCHA (1996), os primeiros estádios de desenvolvimento do colmo, pelo fato de a planta ser muito tenra, apresenta reduzido teor de lignina, predominando no colmo celulose e hemicelulose, ocasionando a falta de resistência e podendo determinar o acamamento. Entretanto, se acamadas, as plantas retornam à posição original, pelo fato de os tecidos estarem pouco lignificados e devido aos movimentos de geotropismo e fototropismo. A máxima quantidade de lignina é atingida a partir da antese; entretanto, com a elevada estatura de planta, aliada aos fatores de ambiente, pode ocorrer o acamamento a partir dessa fase, interferindo no rendimento de grãos e de seus componentes (ROCHA, 1996). É sabido que os programas de melhoramento vem trabalhando ao longo dos anos na busca de constituições genéticas superiores, levando em consideração a interferência do ambiente na capacidade de produção e na estabilidade dos genótipos com relação à resistência ao acamamento. Desse modo, grande parte das constituições genéticas hoje existentes, mesmo com elevada estatura de planta, tendem a apresentar melhor desempenho para o acamamento do que variedades antigas; além disso, interferindo cada vez menos nos componentes do rendimento. Para tanto, além da maior ou menor suscetibilidade dos genótipos de trigo ao acamamento, o estádio que o evento acontece tem determinado o desempenho das cultivares na produção.

Associações de interesse podem ser verificadas entre $\mathrm{Ce} x \mathrm{Ne}^{-1}$, apresentando uma correlação positiva de 0,59 ; porém, nem o $\mathrm{Ne} \mathrm{e}^{-1}$ e o Ce estão associados ao rendimento de grãos, indicando que, mesmo apresentando elevado tamanho de espiga, e número de espiguetas por espiga não permitem maximizar o rendimento utilizando esses caracteres na 
Tabela 3 - Coeficiente de correlação fenotípica de Pearson entre os caracteres de trigo medidos em laboratório: (Ce)= comprimento de espiga; $\left(\mathrm{Ne} \mathrm{e}^{-1}\right)=$ número de espiguetas por espiga; $(\mathrm{Pe})=$ peso de espiga; $\left(\mathrm{Ng} \mathrm{e}^{-1}\right)=$ número de grãos por espiga; $(\mathrm{Pmg})=$ peso de mil grãos; $(\mathrm{PH})=$ peso de hectolitro; $(\mathrm{Rg})=$ rendimento de grãos; e a campo: $(\mathrm{AFML})=$ afilhos férteis por metro linear; $(\mathrm{ACAM})=$ $\%$ de acamamento e (EST)= estatura de planta. FAEM/UFPel, 2004.

\begin{tabular}{|c|c|c|c|c|c|c|c|c|c|}
\hline & $\mathrm{Ce}$ & $\mathrm{Ne} \mathrm{e}^{-1}$ & $\mathrm{Pe}$ & $\mathrm{Ng} \mathrm{e}^{-1}$ & Pmg & $\mathrm{PH}$ & AFML & $\mathrm{Rg}$ & ACAM \\
\hline \multicolumn{10}{|l|}{$\mathrm{Ce}$} \\
\hline $\mathrm{Ne} \mathrm{e}^{-1}$ & $0,59 *$ & & & & & & & & \\
\hline $\mathrm{Pe}$ & 0,36 & $0,54^{*}$ & & & & & & & \\
\hline $\mathrm{Ng} \mathrm{e}^{-1}$ & $0,48^{*}$ & $0,73^{*}$ & $0,87 *$ & & & & & & \\
\hline Pmg & $-0,22$ & $-0,48^{*}$ & $-0,13$ & $-0,47^{*}$ & & & & & \\
\hline $\mathrm{PH}$ & 0,06 & 0,20 & $0,68 *$ & $0,55^{*}$ & $0,52 *$ & & & & \\
\hline AFML & $-0,24$ & $-0,03$ & $-0,31$ & $-0,28$ & 0,23 & 0,27 & & & \\
\hline $\mathrm{Rg}$ & $-0,19$ & 0,08 & 0,37 & 0,27 & 0,20 & $0,71^{*}$ & 0,38 & & \\
\hline ACAM & $-0,13$ & $-0,48^{*}$ & $-0,30$ & $-0,31$ & 0,43 & $-0,28$ & $-0,23$ & $-0,39$ & \\
\hline EST & $-0,29$ & $-0,08$ & $-0,19$ & $-0,25$ & 0,37 & 0,26 & 0,51 & 0,42 & 0,04 \\
\hline
\end{tabular}

* Significativo a 5\% de probabilidade de erro pelo teste t.

seleção indireta. Entretanto, interesse deve ser conferido na associação existente entre PH e Rg, indicando ser o único caráter a ser empregado de maneira eficiente para seleção indireta visando ao incremento no rendimento de grãos, confirmada pela associação positiva apresentada pelo $\mathrm{PH}$ x Pmg de 0,52, PH x Ng e $\mathrm{e}^{-1}$ de 0,55 e, $\mathrm{PH}$ x Pe, com 0,68 de correlação. Observação de interesse também deve ser conferida na associação negativa existente entre o $\operatorname{Ne~}^{-1} \mathrm{x} \operatorname{Pmg}(-0,48)$, onde o aumento no número de espiguetas por espiga acarreta a redução do Pmg, o que indiretamente pode prejudicar o $\mathrm{PH}$ pela associação existente entre $\mathrm{PH} \mathrm{x}$ Pmg. Além disso, o caráter Pe está associado com Ng $\mathrm{e}^{-1}$ e $\mathrm{PH}$, podendo representar uma boa estratégia de seleção indireta para elevar o $\mathrm{PH}$ e $\mathrm{Ng} \mathrm{e}^{-1}$ e, conseqüentemente, o Rg, por apresentar caráter de fácil aferição.

Na tabela 4, estão inseridos os efeitos diretos e indiretos das estimativas de coeficientes de trilha dos componentes indicativos de resistência ao acamamento sobre a variável principal rendimento de grãos. O desdobramento do coeficiente de correlação através da análise de trilha permitiu verificar que a associação existente entre $\mathrm{Ce} \times \mathrm{Ne}^{-1}$ de 0,59 apresentou efeito direto de $(-0,205)$ e maior efeito indireto via $\mathrm{Ng} \mathrm{e}^{-1}(-0,393)$, estabelecendo que a seleção para comprimento da espiga mesmo não maximizando o aumento no rendimento de grãos, tende a reduzir o $\mathrm{Ng}$ $\mathrm{e}^{-1}$ pelo seu efeito negativo. $\mathrm{O} \mathrm{Ne} \mathrm{e}^{-1}$ que evidenciou reduzido efeito direto com $\mathrm{Rg}$ apresentou elevado efeito indireto e negativo com $\mathrm{Ng} \mathrm{e}^{-1}$ de -0,632, também confirmando que a seleção para Rg pelo $\mathrm{Ne} \mathrm{e}^{-1}$ mesmo sendo ineficiente tende a favorecer a redução do $\mathrm{Ng} \mathrm{e}^{-1}$.

Na tabela 3, o caráter Pe não evidenciou associação significativa com rendimento de grãos, exceto para $\mathrm{Ng} \mathrm{e}^{-1}$ e $\mathrm{PH}$; entretanto, na tabela 4, evidenciou elevado efeito direto sobre o rendimento 0,71, podendo representar um caráter eficiente a ser empregado na seleção indireta visando ao incremento no Rg, principalmente pela facilidade de mensuração. Além disso, elevado efeito indireto e negativo foi verificado com $\mathrm{Ng} \mathrm{e}^{-1}(-0,801)$, indicando que a seleção 
Tabela 4 - Estimativa dos efeitos diretos e indiretos dos coeficientes de trilha através de correlações genotípicas sobre o caráter rendimento de grãos (Rg) como variável dependente principal e os caracteres medidos na espiga e o acamamento como variáveis independentes explicativas em dezenove genótipos de trigo. FAEM/UFPel, 2004.

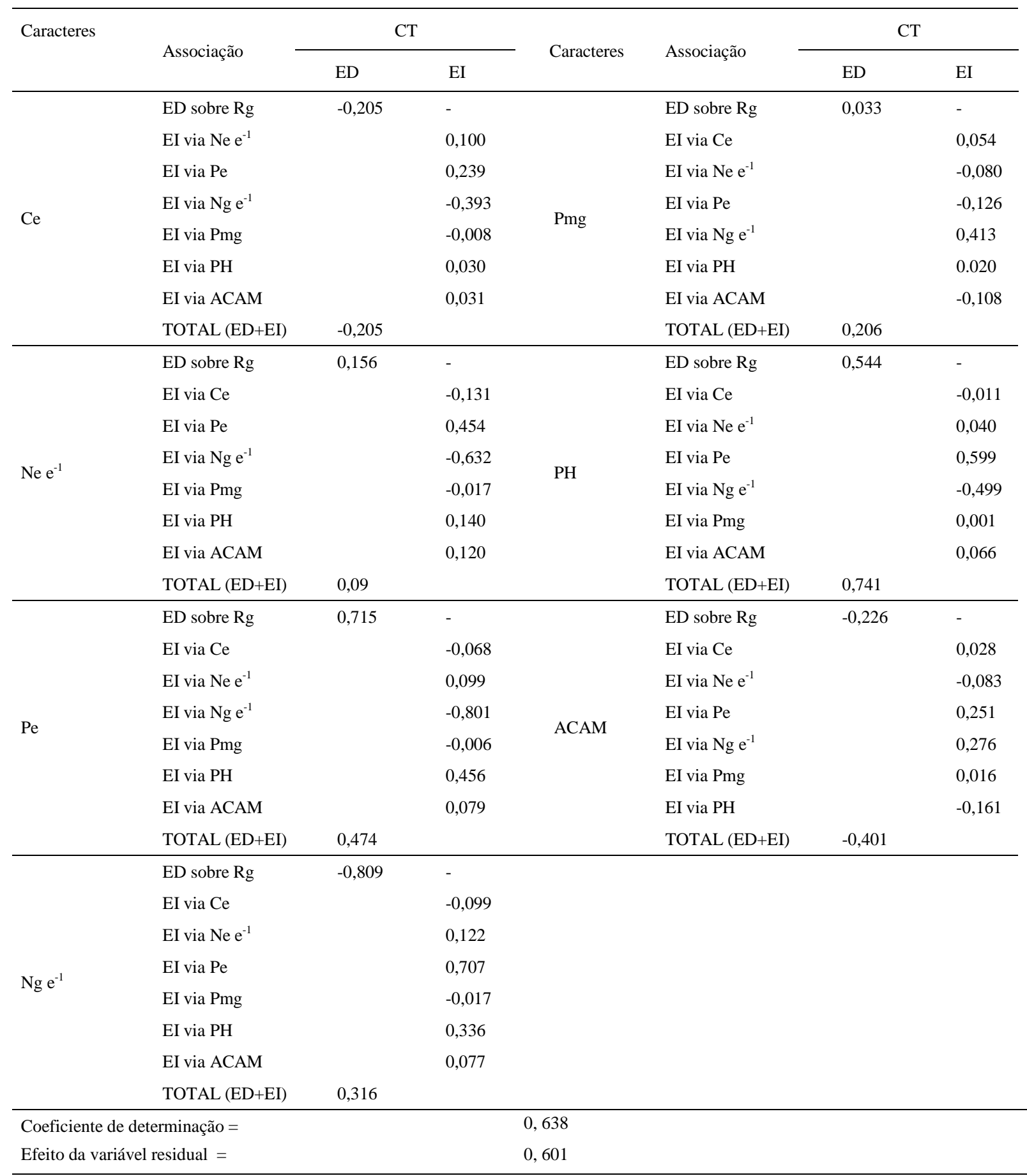

$\mathrm{CT}=$ Coeficiente de trilha; $\mathrm{ED}=$ efeito direto; $\mathrm{EI}=$ efeito indireto; $(\mathrm{Ce})=$ comprimento de espiga; $\left(\mathrm{Ne} \mathrm{e}^{-1}\right)=$ número de espiguetas por espiga; $(\mathrm{Pe})=$ peso de espiga; $\left(\mathrm{Ng} \mathrm{e}^{-1}\right)=$ número de grãos por espiga; $(\mathrm{Pmg})=$ peso de mil grãos; $(\mathrm{PH})=$ peso de hectolitro; $(\mathrm{Rg})=$ rendimento de grãos e $(\mathrm{ACAM})=\%$ de acamamento. 
indireta para rendimento pelo $(\mathrm{Pe})$, mesmo elevando o $(\mathrm{Rg})$, tende a reduzir $\left(\mathrm{Ng} \mathrm{e}^{-1}\right)$, o que pode ser explicado pelo fato de um menor número de sementes elevar o peso de grãos pela melhor partição e acúmulo de fotoassimilados, acarretando aumento no rendimento de grãos. Contudo, quando verificado o efeito indireto do $\mathrm{Ng} \mathrm{e}^{-1}$ com Pe, evidenciou-se elevado efeito indireto e positivo. O Pmg demonstrou maior efeito indireto com $\mathrm{Ng} \mathrm{e}^{-1}$ e reduzido efeito direto para Rg. Entretanto, o PH evidenciou elevado efeito direto com Rg de 0,54 e alto efeito indireto positivo com Pe de 0,59; além disso, apresentou efeito indireto via $\mathrm{Ng} \mathrm{e}^{-1}$ de $-0,49$, compreendendo que tanto o $\mathrm{PH}$ quanto o Pe tendem a elevar o rendimento de grãos, porém tendendo a reduzir o $\mathrm{Ng} \mathrm{e}^{-1}$.

Para o caráter acam, houve efeito direto negativo reduzido para $\operatorname{Rg}(-0,226)$ e indireto positivo para $\mathrm{Pe}(0,251)$ e $\mathrm{Ng} \mathrm{e}^{-1}$ de 0,276 , evidenciando que, mesmo sendo os maiores valores de efeitos diretos e indiretos, estes apresentaram reduzida expressão, indicando pouco efeito do acamamento sobre os componentes do rendimento. Esse fato reforça o que foi verificado, pois, nos estágios anteriores à fase reprodutiva, ocorreu o restabelecimento de alguns genótipos no campo após o acamamento, e mesmo as que permaneceram acamadas apresentaram bons desempenhos de produção. Em aveia branca, as associações e os efeitos diretos e indiretos das diferentes variáveis analisadas quanto aos componentes do rendimento podem apresentar diferentes associações de acordo com os genitores empregados, o que demonstra a necessidade de maior conhecimento das relações genéticas entre genitores utilizados em hibridações, a fim de possibilitar a escolha mais criteriosa de estratégias de seleção a serem empregadas, fundamentais para a otimização do ganho genético.

\section{CONCLUSÃO}

O peso hectolítrico pode ser empregado de maneira eficiente na seleção indireta, visando ao incremento no rendimento de grãos, no peso médio de grãos, no número de grãos por espiga e no peso de espiga. O caráter peso de espiga evidencia elevado efeito indireto sobre o rendimento de grãos, podendo ser empregado na seleção indireta para rendimento, pela facilidade de mensuração. A linhagem TB 951 é indicada como excelente fonte de resistência ao acamamento em trigo, podendo contribuir para elevar o comprimento de espiga, o número de espigueta por espiga, o peso de espiga e o número de grãos.

\section{AGRADECIMENTOS}

Os autores agradecem à Fundação de Amparo à Pesquisa do Estado do Rio Grande do Sul (FAPERGS), ao Conselho Nacional de Desenvolvimento Científico e Tecnológico (CNPq) e à CAPES pelos auxílios financeiros recebidos e pelas bolsas de graduação e de pós-graduação, permitindo a viabilização do trabalho.

\section{REFERÊNCIAS}

BRADY, J. Some factors influencing lodging in cereals. Journal Agricultural Science, v.24, p.209-232, 1934.

CRUZ, C.D. Programa genes: aplicativo computacional em genética e estatística. Viçosa: UFV, 2001. 648p.

CRUZ, P.J. Genética do acamamento em trigo (Trititicum aestivum) e a identificação do caráter para seleção. 2002. 96f. Tese (Doutorado em Genética e Biologia Molecular) Programa de Pós-graduação em Genética e Biologia Molecular, Universidade Federal do Rio Grande do Sul.

CRUZ, P.J. et al. Influência do acamamento sobre o rendimento de grãos e outros caracteres em trigo. Agrociência, v.9, n.1, p.05-08, 2004.

COMISSÃO SUL BRASILEIRA DE PESQUISA DE TRIGO. Recomendações da Comissão Sul-Brasileira de Pesquisa de Trigo para a cultura do trigo. 2003. Passo Fundo: EMBRAPA-CNPT, 2003. 74p.

DOLINSKI, R. et al. Genetic analysis of selected physical properties of the culm of capelle-desprez/bezostya substitution lines. Acta Agronomica Hungarica, v.44, n.3, p.245-254, 1996.

FALCONER, D.S.; MACKAY, T.F. Introduction to quantitative genetics. 4.ed. Londres: Longman Group, 1996. 464p.

FEDERIZZI, L.C. et al. Efeito do acamamento artificial em alguns genótipos de trigo de porte alto e baixo. Ciência Rural, v.24, n.3, p.465-469, 1994.

GRAfIUS, J.E. Components of yield in oats. Agronomy Journal, v.48, p.419-423, 1956

GRAFIUS, J.E.; WIEBE, G.A. Expected genetic gain in yield in small grain: geometrical interpretation. Agronomy Journal, Madison, v.51, p.560-562, 1959.

LI, C.C. Path analysis: a primer. California: California Pacific Grove, The Boxwood, 1975. 347p.

ROCHA, A.B. Características de genótipos de aveia e de trigo e suas relações com a quebra de colmos. 1996. 126f. Dissertação (Mestrado Agronomia) - Faculdade de Agronomia Universidade Federal do Rio Grande do Sul.

SCHEEREN, P.L. Instruções para utilização de descritores de trigo (Triticum sp.) e triticale (Triticun sp.). Passo Fundo: EMBRAPA-CNPT, 1984. 32p. (EMBRAPA-CNPT Documentos, 9). 
STEEL, G.D.; TORRIE, J.H. Principles and procedures of statistics: a biometrical approach. 2.ed. New York: McGrawHill, 1980. 633p.

STODDART, J.L.; LOYD, E.J. Modification by gibberelin of the growth temperature relationship in mutant and normal genotypes of several cereals. Plant Breeding, v.167 n.1, p.364-368, 1986
WRIGTH, S. The theory of path coefficients - a replay to Niles' criticism. Genetics, Austin, v.8, p.239-255, 1923.

ZANATTA, A.C.A.; OERLECKE, D. Efeito de genes de nanismo sobre alguns caracteres agronômicos e morfológicos de Triticum aestivum (L.) Thell. Pesquisa Agropecuária Brasileira, v.26 p.1001-1016, 1991. 